\title{
PERANCANGAN JARINGAN MENGGUNAKAN ROUTER SWITCH CISCO PACKET TRACER PADA KANTOR DISKOMINFOTIK PROVINSI NUSA TENGGARA BARAT
}

\author{
Isnaeni Zulkarnaen', Jannatun Aliyah² \\ ${ }^{1 *}$ Fakultas Rekayasa sistem Universitas Teknologi Sumbawa \\ ${ }^{2}$ Fakultas Rekayasa sistem Universitas Teknologi Sumbawa
}

*Corresponding Author email: ${ }^{1}$ mincinjr77@gmail.com, 2jannatun.aliyah@uts.ac.id

\begin{tabular}{|c|c|}
\hline & Abstrak \\
\hline $\begin{array}{l}\text { Diterima : } \\
\text { Bulan Juni } 2021\end{array}$ & $\begin{array}{l}\text { Pada era globalisasi saat ini perkembangan teknologi semakin maju oleh karena itu } \\
\text { sumber daya manusia di tuntut untuk berkompetensi dalam berbagai bidang. Untuk } \\
\text { menghasilkan sumber daya manusia yang berkompenten. Penelitian ini bertujuan untuk } \\
\text { Merancang Jaringan Komputer Menggunakan Router Switch Cisco Pada Kantor Dinas }\end{array}$ \\
\hline $\begin{array}{l}\text { Diterbitkan : } \\
\text { Bulan Juli } 2021\end{array}$ & $\begin{array}{l}\text { Komunikasi Informasi dan Tatistik Nusa Tenggara Barat. Jenis jaringan yang dirancang } \\
\text { mengacu pada jaringan LAN ( Local Area Network). Perancangan jaringan ini bertujuan } \\
\text { untuk mempermudah tenaga IT dalam menyelasikan pekerjaan dengan kekuatan sinyal } \\
\text { yang stabil dan optimal dengan sinyal yang terbagi pada tiap-tiap sub bidang. Penelitian }\end{array}$ \\
\hline Keyword : Route & ini dilakukan menggunakan metode kualitatif dengan melakukan observasi langsung ke \\
\hline $\begin{array}{l}\text { Switch }{ }^{1}, N D L C^{1}, \\
\text { Cisco }^{3} \\
\text { Paket Tracer }^{\text {Take }}\end{array}$ & $\begin{array}{l}\text { lapangan. Metode pengembangan jaringan yang digunakan dalam penelitian ini ialah } \\
\text { menggunakan metode NDLC (Network Development Life Cycle) dengan tahapan }\end{array}$ \\
\hline
\end{tabular}

\section{PENDAHULUAN}

Pada era globalisasi saat ini perkembangan teknologi semakin maju oleh karena itu sumber daya manusia di tuntut untuk berkompetensi dalam berbagai bidang. Untuk menghasilkan sumber daya manusia yang berkompenten. Lembaga pendidikan Universitas Teknologi Sumbawa sebagai instansi pendidikan yang berperan dalam membentuk karakteristik yang mampu bersaing di dunia kerja diera global saat ini. Pengetahuan akan teori yang telah didapatkan di bangku perkuliahan akan dipadukan dengan pelatihan praktik di lapangan guna memberikan gambaran tentang dunia kerja yang sebenarnya. Dengan adanya program penelitian ini mahasiswa diharapkan untuk mampu menyelesaikan permasalahan yang ada pada suatu instansi dan menanamkan jiwa profesionalitas dalam bekerja.

Penelitian ini dilakukan pada Kantor Diskominfotik Pemerintah Provinsi NTB yang bertempat di Jl. Udayana No. 14, Monjok Bar., Kec. Selaparang, Kota Mataram selama 45 hari. Pemilihan lokasi magang kerja di Kantor Diskominfotik Provinsi NTB Mataram menjadi sasaran yang tepat untuk penulis mengimplementasikan ilmu yang selama ini penulis dapatkan di bangku perkuliahan, dikarenakan sejalan dengan Program Studi yang peneliti tempuh. Kantor Diskominfotik Provinsi NTB memiliki tugas pokok yaitu menyelenggarakan Urusan Pemerintah Bidang Komunikasi dan Informatika, Urusan Pemerintah Bidang Statistik, Serta Urusan
Pemerintah Bidang Persandian yang menjadi kewenangan Daerah Provinsi dan Tugas Pembantuan Yang di tugaskan kepada Daerah Provinsi.

Dalam hal ini peneliti melakukan perancangan sebuah jaringan komputer dengan menggunakan Router Switch Cisco. Router Switch Cisco merupakan salah satu alat yang mempunyai fungsi sebagai pembagi sinyal dan penguat sinyal pada jaringan komputer serta dapat mengenali alamat data yang harus ditransmisikan.

Peneliti berharap apa yang telah dikerjakan dapat memberikan manfaat kepada Dinas Komunikasi Informatika Dan Statistik Nusa Tenggara Barat agar dapat merasakan kenyamanan dalam bekerja tanpa adanya gangguan sinyal yang menghambat pekerjaanya.

\section{LANDASAN TEORI}

Topologi jaringan adalah suatu cara untuk membuat sejumlah komputer saling berhubungan antara komputer satu dengan komputer yang lain. Menurut Andi Kristanto (2003 : 21) topologi jaringan adalah suatu pola dengan sekelompok komputer otonom yang saling terhubung dengan memakai satu protokol komunikasi sehingga semua komputer yang saling terhubung tersebut bisa saling berbagi informasi, aplikasi, sumber daya yang saling menggunakan perangkat keras secara bersamaan, misalnya printer, dan hardisk. 
Adapun macam-macam topologi jaringan diantaranya :

Topologi Star;

$>$ Topologi Bus;

$>$ Topologi Ring;

$>$ Topologi Tree;

$>$ Topologi Mesh.

Jaringan komputer adalah himpunan interkoneksi antara 2 komputer autonomous atau lebih yang terhubung dengan media transmisi kabel atau tanpa kabel (wirelles) (Norton, 1995). Menurut Budhi Irawan (2005 : 5) jaringan komputer adalah suatu system yang terdiriata komputer dan perangkat jaringan lainnya yang bekerja sama untuk mencapai suatu tujuan yang sama. Berdasarkan geografisnya, jaringan komputer terbagi menjadi tiga kelompok, yaitu :

\section{a. Local Area Network (LAN) \\ b. Metropolitan Area Network (MAN) \\ c. Wide Area Network (WAN)}

Alamat IP (Internet Protocol Address atau sering disingkat IP) adalah deretan angka biner antara 32-bit sampai 128-bit yang dipakai sebagai alamat identifikasi untuk tiap komputer host yang berada dalam jaringan internet. Panjang dari angka ini adalah 32-bit (untuk IP versi 4) dan 128bit (untuk IP versi 6) yang menunjukkan alamat dari komputer tersebut pada jaringan internet berbasis TCP/IP.

Menurut Sofana (2008 : 5) OSI Layer (Open System Interconnection) dapat dipandang sebagai panduan umum atau abstact model bagaimana protokol - protokol jaringan dan peralatannya saling berkomunikasi dan bekerja sama. OSI merupakan referensi yang telah digunakan dan disederhanakan menjadi TCP/IP. Protokol OSI terdiri dari 7 layer yang mana masing-masing dari layer tersebut memiliki fingsinya sendiri sendiri.

Layer 7 : Application

Fungsi : Layer yang mendefinisikan pelayanan komunikasi jaringan dalam bentuk aplikasi seperti : Telnet, FTP, HTTP, SSH.

Layer 6 : Presentation

Fungsi : Layer yang mendefinisikan format data seperti ASCII, HTML, JPG dan lainnya yang dikirimkan ke jaringan yang dapat dimanipulasi sehingga bisa di mengerti oleh penerima.

Layer 5 : Session

Fungsi : Layer yang mendefinisikan bagaimana memulai mengontrol dan menghentikan sebuah conversation / komunikasi antar mesin. Contohnya : Kita mengambil uang di mesin ATM dari memasukkan pin sampai dengan mengambil uang yang sebelumnya mesin berkomunikasi dengan server dahulu tentang saldo rekening anda dan jumlah yang anda minta.

Layer 4 : Transport

Fungsi : Layer yang mendefinisikan management dari virtual circuit antar host dalam jaringan yang mengandung rangkaian protocol dan permasalah transportasi data.

Layer 3 : Network

Fungsi : Layer yang Mendefinisikan akhir pengiriman paket data dimana computer mengidentifikasi logical address seperti IP Address bagaimana meneruskan / routing (oleh router) untuk siapa pengiriman paket data.

Layer 2 : Data Link

Fungsi : Layer ini lebih menspesifikan pada bagaimana paket data didistribusikan / ditransfer data melalui media particular atau lebih yang kita kenal seperti Ethernet, hub, dan Switches. Layer 1 : Physical

Fungsi : Layer terendah ini mendefinisikan media fisik dari transmisi paket data dimana protocol digunakan Ethernet pinout, kabel UTP (RJ45, RJ48, dsb) kita bisa perkirakaan layer ini tentang kabel dan konektornya.

Server adalah sebuah sistem komputer yang menyediakan jenis layanan tertentu dalam sebuah jaringan komputer. Server didukung dengan prosesor yang bersifat scalable dan RAM yang besar, juga dilengkapi dengan sistem operasi khusus, yang disebut sebagai sistem operasi jaringan atau network operating system.

Router sering digunakan untuk menghubungkan beberapa network. Baik network yang sama maupun berbeda dari segi teknologinya. Seperti menghubungkan network yang menggunakan topologi Bus, Star dan Ring. Router juga digunakan untuk membagi network besar menjadi beberapa buah subnetwork (networknetwork kecil).

Switch tidak seperti router, switch tidak meneruskan paket ke jaringan lain. Switch hanya menghubung-hubungkan frame dari satu port ke port yang lainnya di jaringan mana dia berada. Secara default, switch memisahkan collision domain. Istilah collision domain adalah istilah di dalam Ethernet yang menggambarkan sebuah kondisi network dimana sebuah alat mengirimkan paket pada sebuah segment network, kemudian memaksa semua alat yang lain di segment tersebut untuk memperhatikan paketnya.

\section{METODE PENELITIAN}

Dalam perancangan jaringan Router Switch, peneliti menggunakan metode NDLC. NDLC merupakan sebuah metode yang bergantung pada proses pembangun sebelumnya seperti perancangan strategi bisnis, daur hidup pengenbangan aplikasi, dan analisis pendistribusian data Metode ini baik digunakan dalam perancangban jaringan. 


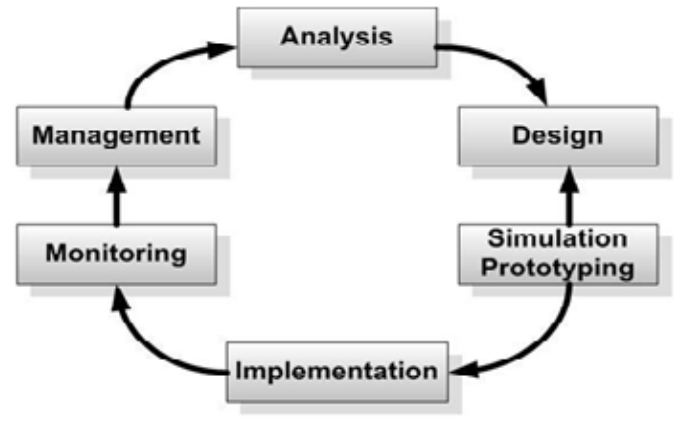

Gambar 1. Metode NDLC (Network Development Life Cycle)

1. Analisis

Tahap awal ini dilakukan analisa kebutuhan, analisa permasalahan yang muncul, analisa keinginan user, dan analisa topologi atau jaringan yang sudah ada saat ini.

2. Design

Membuat design tpologi jaringan interkoneksi yang akan dibangun, diharapkan dengan gambar ini akan memberikan gambaran seutuhnya dari kebutuhan yang ada. Design bisa berupa design struktur topolpogi, design akses data, design tata layout perkabelan, dan sebagainya yang akan memberikan gambaran yang jelas tentang project yang akan dibangun

3. Simulation Prototyping

Beberapa networkers akan membuat dalam bentuk simulasi dengan bantuan tools khusus dibidang network seperti BOSON, PACKET TRACER, NETSIM dan sebagainya. Hal ini dimaksud untuk melihat kinerja awal dari network yang akan dibangun dan sebagai bahan persentasi dan sharing dengan team work lainnya. Namun karena keterbatasan perangkat lunak simulasi ini, banyak para networkers yang hanya mengunakan alat bantu tools VISIO untuk membangun topolgi yang akan didesign.

4. Implementation

Ditahap ini akan memakan waktu yang lamadari tahapan sebelumnya. Dalam implementasi networkers akan menerapkan semua yang telah dirancangdan didesign sebelumnya. Implementasi merupakan tahapan yang sangat menentukan dari hasil atau gagalnya projcet yang akan dibangun.
5. Monitoring

Setelah implementasi tahapan monitoring merupakan tahapan yang penting, agar jaringan komputer dan komunikasi dapat berjalan sesuai dengan keinginan dan tujuan awal dari user pada tahap awal analisis, maka perlu dilakukan kegiatan monitoring.

\section{Management}

Di manajemen atau pengaturan salah satu yang menjadi perhatian khusus adalah malasah policy, kebijakan perlu dibuat untuk membuat atau mengatur agar sistem yang telah dibangun dan berjalan dengan baik dapat berlangsung lama dan unsur reliability terjaga. Policy akan sangat tergantung dengan kebijakan level menajemen dan strategi bisnis perusahaan tersebut. IT sebisa mungkin harus dapat mendukung atau alignment dengan strategi bisnis perusahaan.

\section{HASIL DAN PEMBAHASAN}

\section{a. Hasil Penelitian}

Dalam proses perancangan Peneliti menggunakan metode pengembangan Network Development Life Cycle (NDLC) yang dimana Peneliti hanya pada tahap Analisis, Design, Simulasi Prototype. Secara geografis jaringan pada Dinas Komunikasi Informatika Dan Statistik Nusa Tenggara Barat adalah topologi LAN. Berdasarkan peranan dan hubungan setiap komputer maka jaringan Dinas Komunikasi Informatika Dan Statistik Nusa Tenggara Barat bersifat client server dimana server sebagai penyedia data.

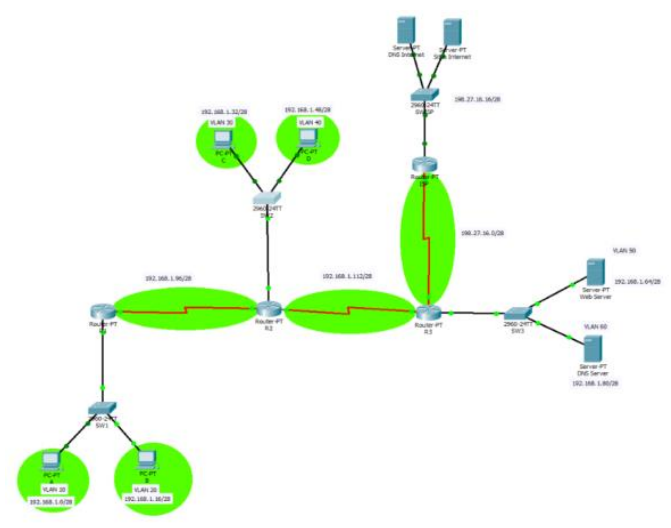

Gambar 2. Desain Perancangan Jaringan 


\section{b. Pembahasan}

1. Pengecekan Konfigurasi Ip Address

Sebelum melakukan test ping dan akses layanan server, perlu dilakukan terlebih dahulu pengecekan pada masing-masing perangkat. Apakah semua perangkat terhubung dengan baik atau tidak. Pengecekan dilakukan dengan perintah "show run" dan "show ip route".

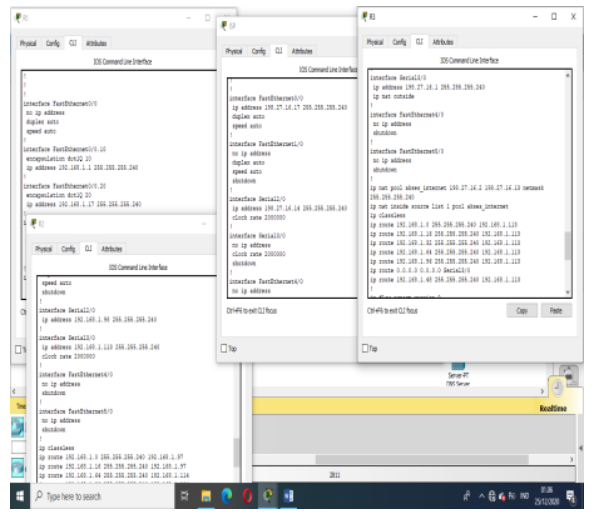

Gambar 3. Alamat Ip yang Berjalan

2. Testing Konfigurasi (Ping)

Test ping perlu dilakukan untuk melakukan pengecekan apakah ip address terpasang dengan benar. Dan jika test ping gagal dilakukan maka pesan yang keluar adalah "request time out". Apabila keluar pesan tersebut maka perlu di periksa ulang pada ip address, apakah benar alamat yang dituju atau salah.

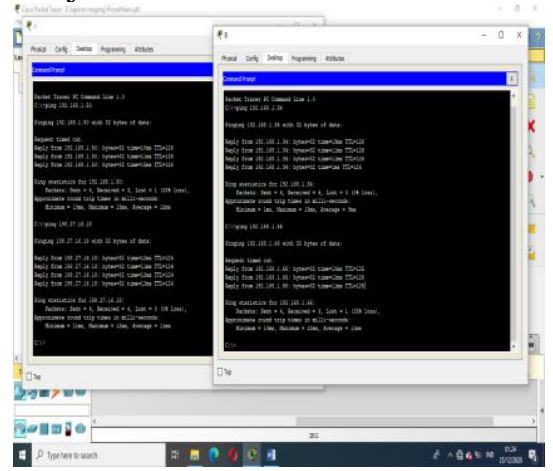

Gambar 4. Konfigurasi Ping

3. Test ping berhasil dilakukantanpa adanya sebuah pesan yang menunjukkan "request time out" yang berarti kegagalan pada sebuah koneksi. menunjukan bahwa jaringan terkoneksi dan pengiriman pesanpun berhasil dilakukan sehingga jaringan sudah siap untuk digunakan.

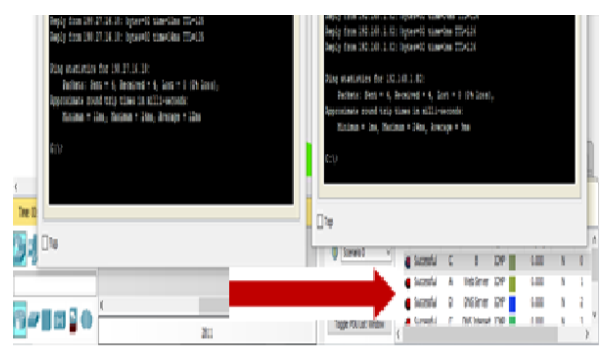

Gambar 5 Pengiriman Pesan Pada Tiap Perangkat

4. Akses Layanan DNS Server

Domain Name Server (DNS) adalah sebuahsistem yang menghubungkan Uniform Resource Locator (URL) dengan Internet Protocol Address (Ip Address). Dengan adanya DNS, untuk menghubungi sebuah wibesite kita tidak perlu lagi mengetikan ip address wibesite tersebut. Untuk mengakses layanan server cukup dengan memasukan sebuah nama domain dan lakukan penelusuran seperti pada gambar di bawah ini dengan nama domain diskominfotik.co.id.

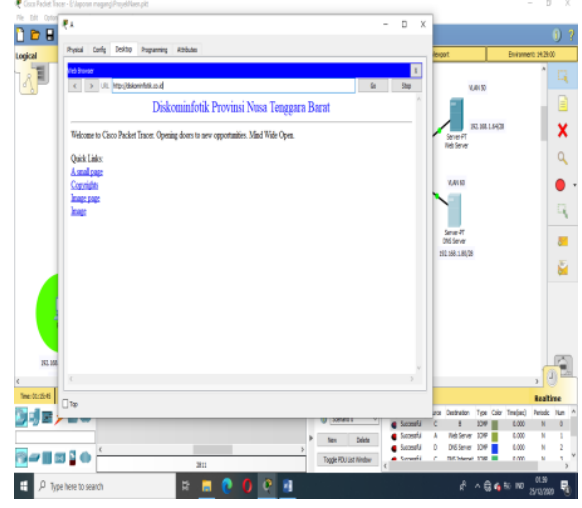

Gambar 6. Layanan DNS Server

5. Akses DNS Situs Internet

Situs internet ini digunakan untuk terhubung ke jaringan internet. Karena setiap instansi atau perusahaan pasti membutuhkan jaringan internet dalam bekerja. Domain yang digunakan adalah situsinternet.com.

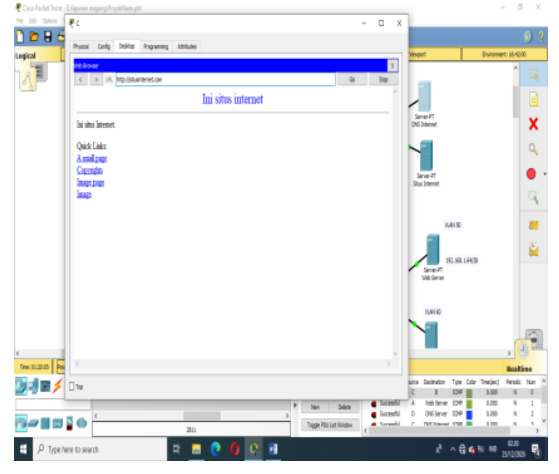

Gambar 7. Akses Layanan Internet 


\section{KESIMPULAN DAN SARAN}

\section{Kesimpulan}

Kesimpulan yang dapat ditarik dari penelitian ini adalah tahapan simulasi pada pada perancangan jaringan komputer Router Switch telah selesai penulis kerjakan dengan baik menggunakan metode NDLC. Dengan terselesaikanya tahapan simulasi perancangan jaringan tersebut, penulis berharap aplikasi jaringan komputer Router Switch dapat segera diimplementasikan sehingga proses pemberian tugas, pelaporan, dan pengecekan laporan tugas oleh atasan di Kantor Dinas Komunikasi Innformatika dan Statistik Provinsi NTB akan menjadi lebih efektif dan efisien.

\section{Saran}

Adapun saran dari peneliti kepada pembaca dan peneliti selanjutnya setelah konfigurasi pada packet tracer, sebaiknya bisa mencoba langsung ke perangkat sesungguhnya agar dapat menambah pengetahuan dalam dunia lapangan kerja.

\section{REFERENSI}

Amazing Light. (n.d.). Retrieved Oktober 1, 2016, from http://www.amazinglight.info/tipejaringan-komputer.html.( di akses tanggal 05 oktober 2016).

Fahrudin, A. N. (2015, 10 1). Tutorial Setting dan Konfigurasi VLAN. Retrieved from omahjaringan.com:

http://omahjaringan.com/tutorialsetting-dan- konfigurasi-vlan/.

Pintar Komputer. (n.d.). Retrieved September 15, 2016, from http://www.pintarkomputer.com/mengen al-jenis-jenis-topologi-yang-ada-padajaringan-wireless/.

Priatna, N. (2013, 05 28). Konfigurasi VLAN menggunakan Switch dan Router pada Packet Tracer. Retrieved from deftutorial.com:

http://www.deftutorial.com/2013/05/ko nfigurasi-vlan-menggunakan-switchdan.html. 